\title{
Twinning European and South Asian river basins to enhance capacity and implement adaptive integrated water resources management approaches - results from the EC-project BRAHMATWINN
}

\author{
W.-A. Flügel \\ Department of Geoinformatics, Friedrich-Schiller University, Jena, Germany
}

\begin{abstract}
The EC-project BRAHMATWINN was carrying out a harmonised integrated water resources management (IWRM) approach as addressed by the European Water Initiative (EWI) in headwater river systems of alpine mountain massifs of the twinning Upper Danube River Basin (UDRB) and the Upper Brahmaputra River Basins (UBRB) in Europe and Southeast Asia respectively. Social and natural scientists in cooperation with water law experts and local stakeholders produced the project outcomes presented in Chapter 2 till Chapter 10 of this publication. BRAHMATWINN applied a holistic approach towards IWRM comprising climate modelling, socio-economic and governance analysis and concepts together with methods and integrated tools of applied Geoinformatics. A detailed description of the deliverables produced by the BRAHMATWINN project is published on the project homepage http://www.brahmatwinn.uni-jena.de.
\end{abstract}

\section{Introduction and research challenges}

The BRAHMTWINN project was funded by the EC within the 6th Framework Program and was carried out between June 2006 and December 2009. Its overall objective was to provide a comprehensive methodology for impact assessment of Climate Change (CC) to the hydrological dynamics and sustainable Integrated Water Resources Management (IWRM) in alpine mountain massifs. CC has become a consistent global threat and research challenge and throughout the world there is rising concern that it will alter a wide spectrum of drivers that are likely to impact river basin hydrological domains in terms of natural and related socio-economic processes (IPCC, 2003; IUCN, 2003). It is common understanding that even if greenhouse gas emissions will be reduced climate change will persist and it is evident that flexible management strategies have to be developed to cope with the resulting impacts on hydrological domains. IWRMas defined by the Global Water Partnership (GWP-TAC, 2000) internationally is accepted to be a proper strategy to address these issues in river basins. The Intergovernmental Panel on Climate Change (IPCC) in a Special Report published Emission Scenarios (SRES) of which the A1B and B1 scenarios (IPCC, 2000) are considered as the most likely ones.

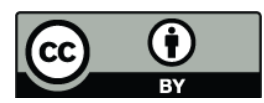

Correspondence to: W.-A. Flügel

(c5wafl@uni-jena.de)
Alpine mountains are a key factor for the hydrological regime of major rivers in the world, such as the Danube in Europe and the Brahmaputra in Asia which have their headwaters in the alpine Alps and the Himalaya respectively. In humid parts of the world alpine mountains provide $30 \%$ to $60 \%$ of downstream freshwater, and in semi-arid and arid environments this figure adds up to $70 \%$ to $95 \%$. Therefore they have been recognized in Chapter 13 of Agenda 21: "As a major ecosystem representing the complex and inter-related ecology of our planet, alpine mountain environments are essential to the survival of the global ecosystem" (EC, 2003).

\subsection{Modelling global climate change}

Present global climate modelling state-of-the-art and results have been published by the 4th Assessment Reports of the IPCC (IPCC, 2007a, b, c). They compile the results from 21 different atmosphere-ocean global circulation models (AOGCM) for the IPCC scenario A1B (IPCC, 2000), evaluated as multi-model datasets (MMD-A1B) in the Program for Climate Model Diagnosis and Intercomparison (PCMDI). According to the 4th IPCC report the temperature projections based on the MMD-A1B models indicate a strong warming over the 21 st century. Warming greater than the global mean is projected for South Asia $\left(3.3^{\circ} \mathrm{C}\right)$ and East Asia $\left(3.3{ }^{\circ} \mathrm{C}\right)$, and significant higher than the global mean in the continental interior of Asia $\left(3.7^{\circ} \mathrm{C}\right.$ in central Asia, $3.8^{\circ} \mathrm{C}$ in Tibet and $4.3^{\circ} \mathrm{C}$ in northern Asia). 


\subsection{Hydrological impacts of climate change}

Glacier retreat and permafrost thaw in high mountains e.g. the Alps, Himalaya and the Quinghai-Tibetan Plateau have presently reached an extent and speed that are without historical precedence (Frauenfelder et al., 2005; Karma et al., 2003; Paul et al., 2004; Ren et al., 2004; Subba, 2001). This is likely to have substantial impacts on the hydrological dynamics, resulting in a greater variability in precipitation and stream flows, increasing intensity of extreme events comprising water quantity and water quality. Declining dry season discharge in rivers of such kind is expected to have major impacts on their economic and ecological services, and will additionally have unforeseen socio-economic consequences for rural and urban development (Kääb et al., 2005; Morrison and Gleick, 2004). Changing discharge regimes from glacier and snowmelt fed rivers impact the implementation of IWRM both in the urban and rural domain and are likely to change vulnerabilities of sensitive management systems with respect to floods and erosion.

Considering the geographic distribution of glaciers in alpine mountains, the global dimension of this phenomenon becomes obvious (IUCN, 2003; Querner, 2002), and today diminishing glacier resources become an international affair as rivers such as the UDRB and the UBRB provide downstream countries with essential water resources to sustain food production, socio-economic development and the environment.

\section{Project objectives}

BRAHMATWINN is addressing these issues with respect to sustainable IWRM in river systems of alpine mountain massifs to cope with CC impacts, and to transfer professional IWRM expertise and Geoinformatics tools developed in Asia and Europe. This was done based on case studies carried out in two twinning European and Asian river basins: The Upper Danube River Basin (UDRB) in Europe, and the Upper Brahmaputra River Basin (UBRB) in Southeast Asia. Meanwhile the UDRB has been subject of various IWRM studies and analysis the UBRB has not been studied and discussed in such comprehensive and integrated context before.

The overall objective of BRAHMATWINN was to enhance and improve capacity to carry out a harmonised integrated water resources management (IWRM) approach as addressed by the European Water Initiative in headwater river systems of alpine mountain massifs in respect to impacts from likely climate change, and to transfer professional IWRM expertise, approaches and tools based on case studies carried out in twinning European and Asian river basins. The overall objective was achieved by means of the following scientific technological objectives (STO):
- STO 1: Assessment of basins atmospheric climate system and downscaling of GCM climate change scenarios to a regional hydrological basin scale, to evaluate the basins adherence to present climate conditions, development of appropriate procedures for modelling likely climate parameter scenarios applied in projective climate modelling exercises.

- STO 2: A comprehensive assessment and analysis of the natural environment (NE) comprising e.g. runoff, groundwater, glaciers, permafrost, terrain, land use, land cover, and eco-hydrological research to derive the interactive dynamics of the system's components.

- STO 3: Assessment of the system's human dimension (HD) accounting for water related issues of socioeconomic vulnerability to environmental stress (water quality, water demand and allocation), gender equity in respect to water allocation and labour division, and considering the political structures and policies pertaining to the basins.

- STO 4: Analysis of present traditional and conceptual IWRM practices and knowledge regarding water quantity and quality, user demands, user conflicts, resource allocation and its potential for adaptation to cope with likely impacts of changing flow regimes.

- STO 5: Transformation of the results obtained in STO 1 till STO 4 to a set of integrated indicators suitable to quantify the present system status and to evaluate the outcome of "what-if?" scenario modelling addressed in STO 9.

- STO 6: Application of the DANUBIA model in the UDRB and their adaptation to the monsoonal UBRB for modelling their snowmelt driven hydrological dynamics, to reproduce observed periods of floods and low flow that require adaptive IWRM strategies and to explore likely hydrological changes related to projected climate time series obtained from STO 1.

- STO 7: Development of likely assumptions for "whatif?" scenarios based on the SRES published by the IPCC (2000) for use in STO 9 and evaluation of integrated indicators from STO 5 to identify and quantify system changes.

- STO 8: Development and implementation of a IWRM toolset to develop and evaluate adaptive IWRM strategies jointly with the stakeholders communities and to identify intervention options by means of the provided DANUBIA model, the River Basin Information System 


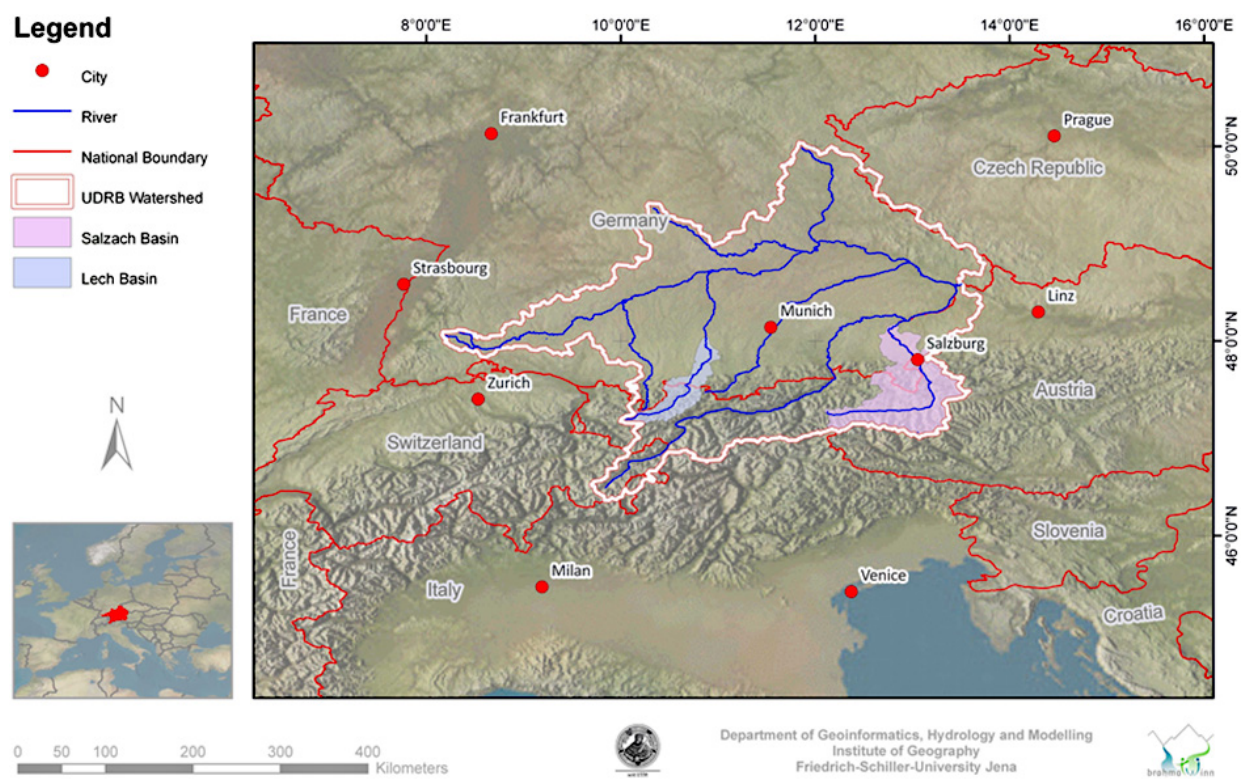

Figure 1. Upper Danube River Basin (UDRB) and its tributary countries in Europe.

(RBIS) and the NetSyMod approach supported by the Mulino-DSS tool ${ }^{1}$.

- STO 9: Development of adaptive IWRM options for climate change mitigation and adaptation by means of the IWRM toolset developed in STO 8 and related to impacts of likely "what-if?" IPPC climate change scenarios derived from STO 7, and discussed with stakeholders with respect to proposed IWRM action plans.

\section{Twinning river basins}

Two twinning basins from Europe and South-East Asia have been selected for the BRAHMATWINN project and European and Asian scientists jointly investigated and analysed different aspects related to the subject within altogether nine work packages (WP) related to the STOs described above. The twinning basins are briefly described as follows:

1. The Danube River basin $\left(A=801463 \mathrm{~km}^{2}, Q_{\text {mouth }}\right.$ $\left.=6460 \mathrm{~m}^{3} \mathrm{~s}^{-1}\right)$ shared by 18 countries is the second largest river basin in Europe (ICPDR, 2005). The Upper Danube River Basin (UDRB), is shown in Fig. 1 and is

${ }^{1}$ The methodology and software tool developed by the MULINO project is designed to support Competent Authorities in the development of RBMPs in all instances in which there are choices to be made between alternative options and with the involvement of stakeholders. The methodology facilitates the integration of environmental, social and economic concerns and facilitates involvement of interested parties in the formulation of strategies and decisions. The project results describing the methodology and the software tool are freely available at the project web site (http://siti.feem.it/mulino/) defined as the drainage area upstream of the river gauge "Achleiten", located just downstream of the mouth of the Inn River into the Danube River near Passau. It covers altogether $76653 \mathrm{~km}^{2}$ with the majority in Germany (73\% in Baden Württemberg and Bavaria) and Austria (24\%), and the remaining 3\% in Switzerland, Italy and the Czech Republic.

2. The Brahmaputra River basin, the mainstream of which originates from the ChemaYundung glacier on the Tibetan plateau, is the biggest trans-Himalayan river basin ( $\left.A=938000 \mathrm{~km}^{2} ; L=2880 \mathrm{~km}\right)$, encompassing parts of the territory, ecosystems, people, economies and politics of China, Bhutan, Nepal, India and Bangladesh. The Upper Brahmaputra River Basin (UBRB) shown in Fig. 2 is defined upstream of the town Guwahati in Assam, NE-India, and for the modelling exercises has been calculated to an area of about $514717 \mathrm{~km}^{2}$. The UBRB is shared mainly by China $\left(282950 \mathrm{~km}^{2}\right)$, Bhutan $\left(43546 \mathrm{~km}^{2}\right)$ and NE-India $\left(188111 \mathrm{~km}^{2}\right)$, where in Assam the river forms a flood plain in front of the Himalaya with a braided channel pattern and severe bank erosion.

Because of the macro-scale size of both twinning basins two reference catchments of the Lech river in Germany and the Salzach river in Austria shown in Fig. 1 and three reference catchments of the Lhasa river in Tibet, China, the Wang Chu river in Bhutan and the Brahmaputra flood plan in Assam, India shown in Fig. 2 have been selected for detailed studies in the UDBR and the UBRB respectively. 


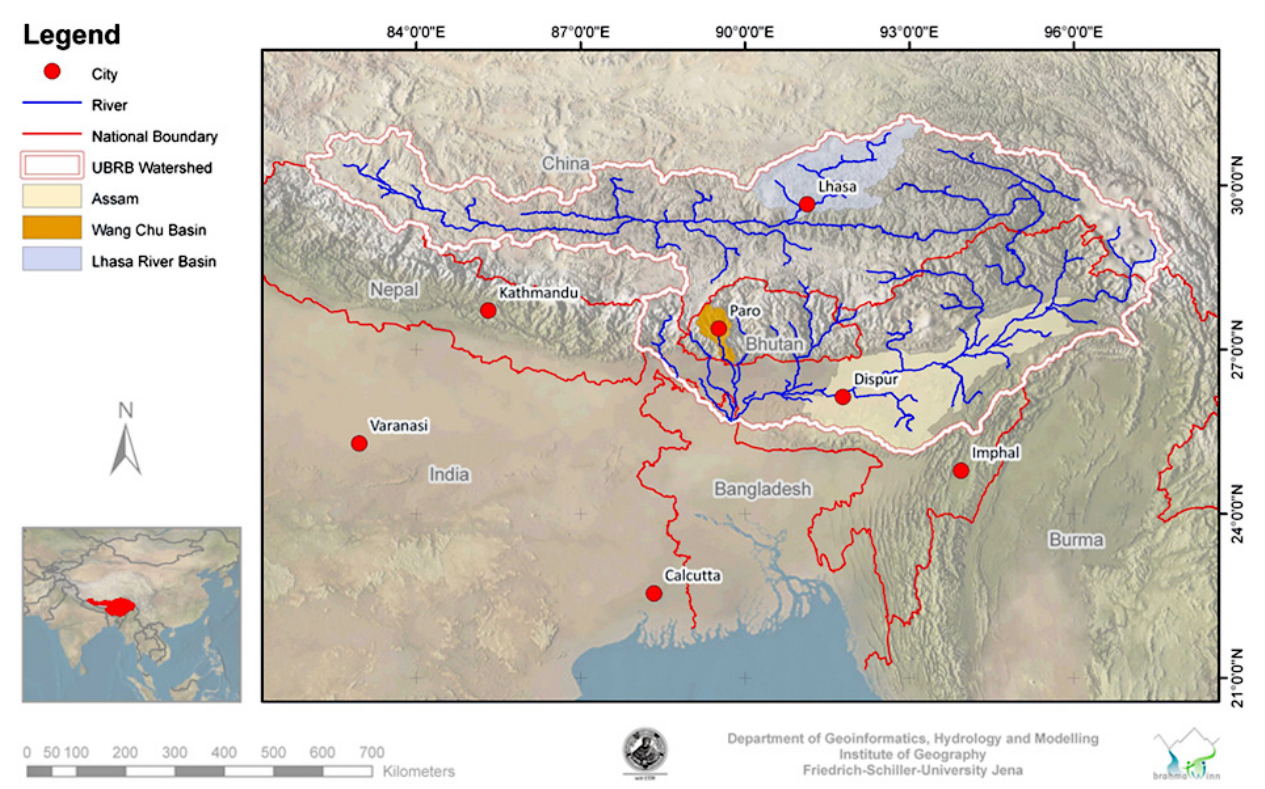

Figure 2. Upper Brahmaputra River Basin (UBRB) and its tributary countries in Asia.

\section{Scientific methods applied}

The methodological approach applied in BRAHMATWINN to a large extent is based on concepts, methods, and software technologies from Geoinformatics, i.e. Geographic Information Systems (GIS), remote sensing and distributed water and solute modeling. They have been integrated within BRAHMATWINN together with the CC modeling, the socio-economic analysis and evaluations into an Integrated Land and Water Resources Management System (IWRMS) that is based on a decision information support tool (DIST) named DanubeRBIS for the UDRB and BrahmaRBIS for the UBRB respectively. They are accessible for testing for interested users from the project homepage http://www.brahmatwinn.uni-jena.de.

\subsection{Applied Geoinformatics in IWRM}

As sustainable IWRM applies a holistic systems approach (Flügel, 2000) that accounts for scale related system process dynamics integrated Geoinformatics toolsets are required that offer methods and technologies for multi-scale system assessment, modelling and analysis. The Jena Environment System Analysis Toolset (JESAT) provides these software components to carry out such an integrated river basin investigation (Flügel, 2009).

Applied Geoinformatics in this respect concerns the spatial assessment and analysis of landscape systems integrating their natural environment and human dimension and applies innovative software and hardware technologies providing the information required to adapt towards sustainable IWRM. The potential of applied Geoinformatics in IWRM can be described with respect to the BRAHMATWINN project as follows:

1. Model results obtained from the different AOGCM deliver information for model grids cells that are by far too large for integrated water resources management (IWRM). They have to be downscaled by means of models and methods developed by means of Geoinformatics.

2. Changing land use and land cover (LULC), i.e. by retreating glaciers in alpine mountains is frequently occurring in remote areas with no or only limited access. Remote sensing and GIS both are Geoinformatics technologies that provide the means for a multi-scale comprehensive LULC classification and process oriented analysis, which in turn will deliver process based landscape model entities for water and solute transport modelling.

3. Efficient and sustainable IWRM depends on hydrological measurements of high quality obtained from a sufficient dense hydrometric infrastructure. In alpine mountain massifs and in particular in the Himalayathere is a considerable lack of both of these IWRM prerequisites. Geoinformatics provides the means, i.e. geo-statistics and process modelling tools to regionalize the required input data.

4. Adapting IWRM to changing environment conditions, i.e. to on-going climate change requires appropriate model tools that are able to represent the hydrological processes that control the river basin water balance and its water and solute transport dynamics. These 
models apply model entities derived by Geoinformatics, i.e. from the Response Units (RU) landscape model (Flügel, 1995; Flügel and Märker, 2003) and attribute the latter by means of remote sensing and GIS analysis.

5. Applied in "what-if?" scenario analysis these modelling tools permit predictions of changing water balances, discharge regimes and water resources regeneration and support IWRM decision making by means of the IWRMS developed.

\section{Results achieved and deliverables provided}

WP 2 till WP 10 of the BRAHMATWINN project relate to the STO 1 till STO 9 presented in Sect. 2 and produced research results and deliverables which are presented and discussed in Chapter 2 till Chapter 10 of this volume. The detailed descriptions of the deliverables produced in WP 2 till WP 10 for the UDRB and the UBRB have been input to the DanubeRBISand the BrahmaRBIS respectively and have been published on the BRAHMATWINN homepage (http://www.geoinf.uni-jena.de).

\section{Contributions to sustainable IWRM}

BRAHMATWINN addressed likely climate change impacts triggered by rising temperatures and the alteration of precipitation regimes, on the snow and glacier melt driven hydrology and water balance of river basins with headwaters in alpine mountain massifs. The project elaborate on the consequential vulnerability of present IWRM and river basin management that have been persistent in these basins during the past decades and proposed approaches and technologies to design adaptive IWRM strategies. Snow melt driven river basins and their respective mountain massifs have a global distribution and consequently the objectives, results and findings of BRAHMATWINN have a global relevance as well. The project furthermore provided scientifically based, reproducible IWRM information and analysis toolsets that are of value for conflict disputes to all negotiating parties.

\subsection{Strategic IWRM impact of BRAHMATWINN}

Water has an economic value in all its competing uses and is recognized as a basic resource that by its availability and quality is controlling the socio-economic development, quality of livelihoods, sustainability and prosperity. In this regard BRAHMATWINN provided required knowledge and capacity building in respect to a scientifically based sustainable IWRM that will contribute towards the targets set out in the Millennium Development Goals (MDG) as described by the Global Water Partnership (GWP, 2004).

Sustainable IWRM aims to distribute water in sufficient quantity and quality, based on detailed knowledge of the regeneration potential inherent in the hydrological regime of the river basin and balance this potential against projected demands. BRAHMATWINN accounted for this by a comprehensive assessment of the interactive dynamics between the natural environment (NE) and its human dimension (HD), and present system vulnerabilities have been classified considering socio-economic and technological aspects of water use and their spatial distribution.

Accounting for the different European and Asian domains of the twinning basins the strategic IWRM impact of BRAHMATWINN can be described as follows:

1. BRAHMATWINN did not devise one plan for IWRM and river basin management in the twinning basins, but instead built on and supported efforts of the IWRM processes already in place by providing a comprehensive basin assessment methodology, integrated indicators for use in an IWRMS toolset, respective capacity building and dissemination. The latter contributed to generate awareness for an integrated holistic perspective aiming at better water resources management.

2. Each basin's tributary country or region has its specific natural environment (NE) and human dimension (HD), a history of water use, cultures and customs, different situation of economic development, and various value judgement exists that is based on these. BRAHMATWINN by its approach and IWRMS toolset accounted for the real situation and value judgement of each country or region and is building on them in the development and evaluation of adaptive IWRM options.

3. To realize IWRM, appropriate legal systems, administrative systems, implementation systems and organizations are required, and BRAHMATWINN provided means to identify and recommend such governance structures.

4. Impact on resolving trans-boundary conflicts was addressed by providing sufficient and scientifically sound information for the negotiating parties to identify "win-win", benefit sharing situations with relevance to IWRM. Coevally assistance to establish mutual cooperation through regional networks maintained by countries and organizations that have similar situations and experiences in terms of geographical and meteorological conditions and water utilization has been provided.

5. Areas in which the processes triggered by ice-snowpermafrost melting are in rapid expansion (Kääb, 2005) and have a significant potential for generating GLOFS (Huggel et al., 2003) have been identified. A methodology has been provided, that combines remote sensing with complement surveys and has successfully been tested in the Alps (Fabre and Ribolini, 2003; Haeberli and Beniston, 1998; Kääb et al., 2003; Paul et al., 2004). 


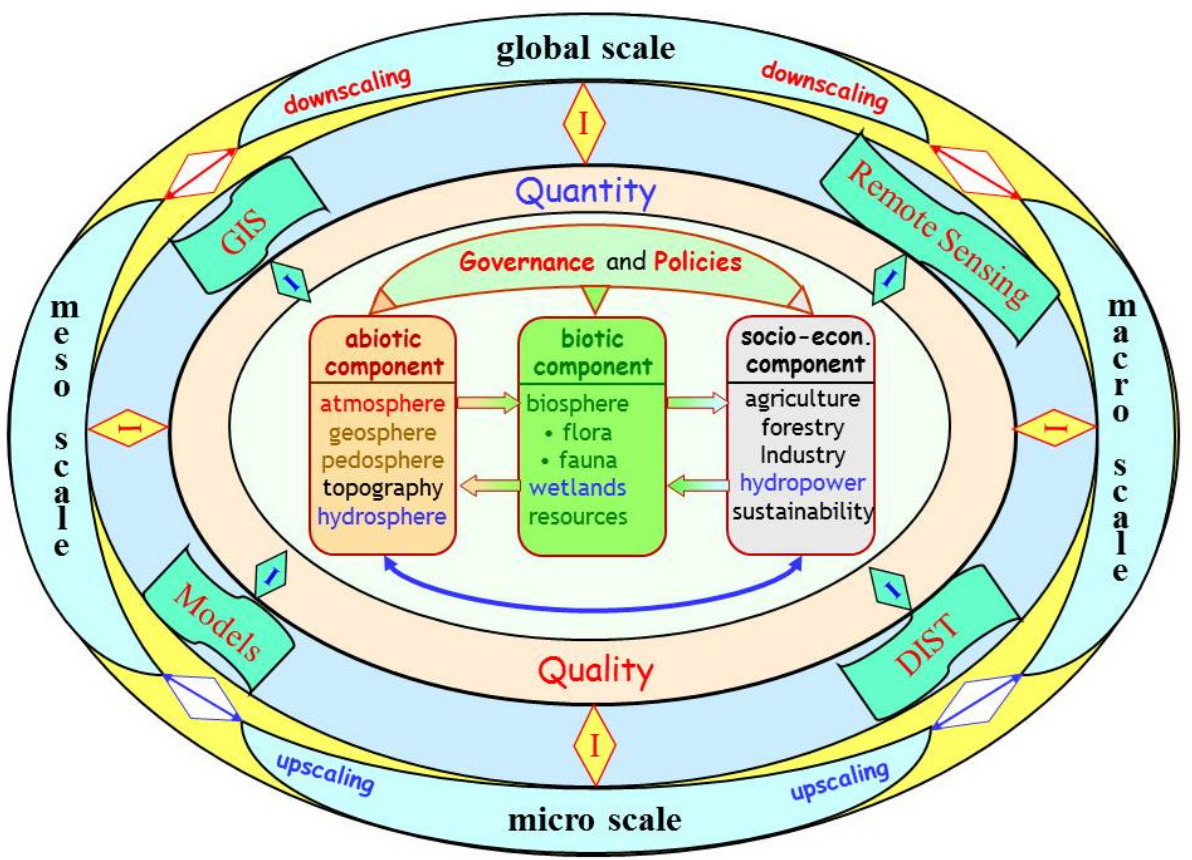

Figure 3. Holistic system approach applying integrated methods from Geoinformatics.

\subsection{Innovative aspects}

By its interdisciplinary collaboration that combined scientists from systems analyses, socio-economy, water law and policy, natural sciences, engineering and computer sciences the innovative potential of BRAHMATWINN comprises the following components:

\subsubsection{Holistic systems approach}

To understand the interactionsbetween the natural environment (NE) and its human dimension (HD)to predict, quantify and evaluate scale related CC impacts for adaptive IWRM, an integrated holistic approach is required that utilizes synergetic integration methods from socio-economic as well as natural science and technologies from Geoinformatics. The needfor such a holistic systems analysis fostering an integrated view on society and nature including their dynamic feedback interactions has also been identified by the UNESCO Biosphere Reserve Integrated Monitoring Programas as a persistent research challenge. It is schematically shown in Fig. 3 and can be described as follows:

1. IWRM within a river basin concerns three interactively linked core compartments comprising the abiotic and biotic components of the natural environment (NE) and the socio-economic components of its human dimension (HD). They are interfaced by governance regulations and are assessed and quantified by means of integrated indicators (Schulting, 2000; Pykh et al., 2000; GWP, 2004) identified by applying the
DPSIR approach proposed by the European Environment Agency (EEA) (http://glossary.en.eea.europa.eu/ terminology/sitesearch?term=DPSIR).

2. Each of the three components has aspects related to the quality and quantity of water resources and their regenerative dynamics. The latter is differently distributed within the basin depending on the interactions between the three core elements and is represented by the regionalization approach applied. The finding will be used to design realistic "what-if?" scenarios for adaptive IWRM and mitigation.

3. Adaptive Geoinformatics methods including GIS, remote sensing, data base management systems (DBMS) and physical based models are techniques composing the toolset to identify, analyse, simulate and regionalize the generic and regional aspects revealed from the core component assessment and analysis done in (1) and (2) respectively. They comprise the tools required to quantify and analyse indicators regarding their spatial distribution and temporal dynamics and to design and evaluate adaptive IWRM options and recommendation (Gonzales, 2002).

4. Methods provided by (3) are means to develop appropriate IWRM tools that have been tested and adapted to the specific conditions and scales of the twinning basin in Europe and Asia. The IWRMS toolset developed by BRAHMATWINN is building on the DANUBIA hydrological model, the River Basin Information System 
(RBIS) and the NetSyMod approach supported by the Mulino-dss tool (Ludwig et al., 2003; Flügel, 2007; Giupponi et al., 2004; Mysiak et al., 2005).

5. Scale issues are indicated by the outer layer in Fig. 3 and are accounted for by applying the well tested Response Units (RU) regionalization concept (Flügel, 1995). The latter will be classified by means of integrated indicators derived from (1) and (2) and are delineated by GIS analyses as Water Resources Response Units (WRRU) representing specific assemblies of the abiotic, biotic and socio-economic core compartments that control their interactive functioning within IWRM. These knowledge based WRRU permit regional upscaling and downscaling and spatial evaluation of IWRM options (Turner, 1989; Bartel, 2000).

6. The innovative methodical integration process is facilitated in BRAHMATWINN by amalgamating the concept of integrated indicators (rhombi in Fig. 3) with the regionalization concept of WRRU delineated by means of GIS analysis. Both concepts are process based and rely on the same holistic river basin analyses to integrate the spatial heterogeneity within the basin. In result they will yield regional distributed, process based IWRM units which offer an extended potential for the development, distributed modelling and spatial evaluation of adaptive sustainable IWRM options.

\subsubsection{Integration of water law and gender issues}

Innovative strategies for adaptive sustainable IWRM comprise methods of system assessment, modelling, socioeconomic and institutional vulnerability mapping. This approach - innovative in the twinning basins - allows for the recommendation of appropriate integrated key indicators of both a physical and socio-economic environment monitored to maintain the adaptive nature of the IWRM. The innovative character of the IWRM is furthermore enhanced by giving special attention to the implementation of water law and gender issues with relevance to IWRM.

- The integration of water law is essential when assessing IWRM on a national and trans-boundary level, but is often a "missing link" within IWRM interdisciplinary research projects. Poor communication between scientists, stakeholders, decision-makers and water law experts often results in barriers to the uptake and implementation of good science and the development of effective laws. Transparent, enforceable and responsive policies supported by legal frameworks for implementation - including water treaties, laws and regulations can assist in defusing water related conflict disputes and enhancing resilience to climate change and the impacts of water scarcity.
- The role of women in IWRM has been recognized worldwide, as often women manage crops, oversee land and water resources, and provide valuable knowledge and expertise for the development of adaptive IWRM strategies and mitigation. This is confirmed by a World Bank study (2003) stating that gender issues are essential for countries' economies, and a precondition, for environmental conservation, sustainable development and human security. The holistic systems approach adopted by BRAHMATWINN accounts for these gender relationships in terms of water allocation and distribution, labour division and shared water related economic responsibilities that likely will be affected by climate impacts to IWRM, e.g. water access during droughts.

\section{Conclusions and recommendations}

BRAHMATWINN at the national level contributed to research activities and existing IWRM action plans, such as the Danube Regional Project (ICPDR, 2005) in the UDRB or the South Asia Water Analysis Network (SAWAN) initiated in 1999 (http://www.wwfpak.org/toxics_sawan.php). At the European level BRAHMATWINN contributed to the ongoing efforts within the UDRB to implement the Water Framework Directive (WFD) and the principles of IWRM as described by the WSSD in Johannesburg in 2002. By integrating NetSyMod into the IWRMS toolset the management of natural and human resources was promoted by the simultaneous involvement of experts, complemented by the involvement of interested actors in a generic participatory process dealing with the management of the environmental resources.On a global scale BRAHMATWINN strengthened the efforts of "sustainable development" and the holistic approach of BRAHMATWINN is contributing to the implementation of the Global Water Partnership (GWP) within Europe and Asia that considers holistic IWRM activities as a supporting prerequisite to reach the Millennium Development (GWP, 2004).

Acknowledgements. The author acknowledges the financial support of the European Commission which funded this project within the 6th Framework Program under Contract No. 036952. The contribution of all project partners and numerous stakeholders in both twinning basins is highly appreciated and acknowledged as well as it was a prerequisite for the successful completion of the project.

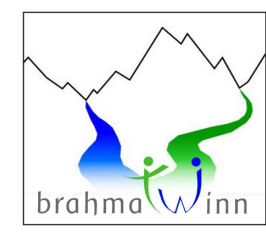

The interdisciplinary BRAHMATWINN EC-project carried out between 2006-2009 by European and Asian research teams in the UDRB and in the UBRB enhanced capacities and supported the implementation of sustainable Integrated Land and Water Resources Management (ILWRM). 


\section{References}

Bartel, A.: Analysis of Landscape Pattern: Towards a 'Top Down' Indicator for Evaluation of Landuse, Ecol. Model., 130, 1-3, 8794, 2000.

European Commission (EC): Water for Life, EU Water Initiative, International Cooperation - from knowledge to action, $26 \mathrm{pp}$., 2003.

Fabre, D. and Ribolini, A.: The lower discontinuous permafrost Boundary in the Argentera Massif (Maritime Alps, Italy): insight from rock glacier geoelectrical soundings, Proceedings of the 8th International Conference on Permafrost, Extended Abstracts on Current Research and Newly Available Information, 33-34, 2003.

Flügel, W.-A.: Delineating Hydrological Response Units (HRU's) by GIS analysis for regional hydrological modelling using PRMS/MMS in the drainage basin of the River Bröl, Germany, Hydrol. Process., 9, 423-436, 1995.

Flügel, W.-A.: Systembezogene Entwicklung regionaler hydrologischer Modellsysteme, Wasser \& Boden, 52, 3, 14-17, 2000.

Flügel, W.-A.: The Adaptive Integrated Data Information System (AIDIS) for global water research, Water Resources Management (WARM) Journal, 21, 199-210, 2007.

Flügel, W.-A.: Applied Geoinformatics for sustainable IWRM and climate change impact analysis, Technology, Resource Management \& Development, 6, 57-85, 2009.

Flügel, W.-A. and Märker, M.: The Response Units Concept and Its Application for the Assessment of Hydrologically Related Erosion Processes in Semiarid Catchments of Southers Africa, ASTM-STP 1420, 163-177, 2003.

Frauenfelder, R., Zemp, M., Haeberli, W., and Hoelzle, M.: Worldwide glacier mass balance measurements: trends and first results of an extraordinary year in Central Europe, Ice and Climate News, 6, 9-10, 2005.

Giupponi, C., Mysiak, J., Fasio, A., and Cogen, V.: MULINO: Multi-Sectoral, Integrated and Operational Decision Support System for Sustainable Use of Water Resources at the Catchment Scale, Math. Comput. Simulat., 64, 13-24, 2004.

Global Water Partnership - Technical Committee (GWP-TEC): “...Integrated Water Resources Management (IWRM) and Water Efficiency Plans by 2005" Why, What and How?, TEC Background Paper, No. 10, 45 pp., 2004.

Gonzalez, R. M.: GIS-assisted joint learning: a strategy in adaptive management of natural resources, in: Adaptive management: from theory to practice, edited by: Oglethorpe, J. A. E., IUCN, Gland, Switzerland and Cambridge, UK, 15-38, 2002.

GWP TAC: Background Paper No. 4, Integrated Water Resources Management, Global Water Partnership, Stockholm, Sweden, 2000.

Haeberli, W. and Beniston, M.: Climate change and its impact on glaciers and permafrost in the Alps, Ambio, 27, 258-265, 1998.

Huggel, C., Kääb, A., Haeberli, W., and Krummenacher, B.: Regional-scale GIS-models for assessment of hazards from glacier lake outbursts: evaluation and application in the Swiss Alps, Nat. Hazards Earth Syst. Sci., 3, 647-662, doi:10.5194/nhess-3-647-2003, 2003.

International Commission for the Protection of the Danube River (ICPDR): The Danube River Basin District, Part A and B, ICPDR Document IC/084, 18 March 2005, 191 pp., 2005.
Intergovenmental Panel on Climate Change (IPCC): Emissions Scenarios, A Special Report of IPCC Working Group III, 27 pp., 2000.

Intergovernmental Panel on Climate Change (IPCC): Good Practice Guidance for Land Use, Land-Use Change and Forestry, 2003.

Intergovernmental Panel on Climate Change (IPCC): Climate Change 2007, The Physical Science Basis, Contribution of Working Group I to the Fourth Assessment Report of the IPCC, 2007a.

Intergovernmental Panel on Climate Change (IPCC): Climate Change 2007, Impacts, Adaption and Vulnerability. Contribution of Working Group II to the Fourth Assessment Report of the IPCC, 2007b.

Intergovernmental Panel on Climate Change (IPCC): Climate Change 2007, Mitigation of Climate Change. Contribution of Working Group III to the Fourth Assessment Report of the IPCC, 2007c.

IUCN: Change. Adaptation of Water Management to Climate Change, IUCN, Gland, Switzerland and Cambridge, UK, ix + 53 pp., 2003.

Kääb, A.: Combination of SRTM3 and repeat ASTER data for deriving alpine glacier flow velocities in the Bhutan Himalaya, Remote Sens. Environ., 94, 463-474, 2005.

Kääb, A., Wessels, R., Haeberli, W., Huggel, Ch., Kargel, J. S., and Khalsa, S. J. S.: Rapid ASTER imaging facilitates timely assessment of glacier hazards and disasters, EOS Transact., AGU, 84(13), doi:10.1029/2003EOI130001, 2003.

Kääb, A., Reynolds, J. M., and Haeberli, W.: Glacier and permafrost hazards in high mountains, in: Global Change and Mountain Regions (A State of Knowledge Overview), Advances in Global Change Research, edited by: Huber, U. M., Bugmann, H. K. M., and Reasoner, M. A., Springer, Dordrecht, 225-234, 2005.

Karma, T., Ageta, Y., Naito, N., Iwata, S., and Yabuki, H.: Glacier distribution in the Himalayas and glacier shrinkage from 1963 to 1993 in the Bhutan Himalayas, Bulletin of Glaciological Research, 20, 29-40, 2003.

Ludwig, R., Mauser, W., Niemeyer, S., Colgan, A., Stolz, R., Escher-Vetter, H., Kuhn, M., Reichstein, M., Tenhunen, J., Kraus, A., Ludwig, M.,Barth, M., and Hennicker, R.: Web-based modelling of energy, water and matter fluxes to support decision making in mesoscale catchments - the integrative perspective of GLOWA-Danube, Phys. Chem. Earth, 28, 621-634, 2003.

Morrison, J. and Gleick, P.: Freshwater Resources: Managing the Risks Facing the Private Sector, Research Paper, Pacific Institute (www.pacinst.org), August 2004, 16 pp., 2004.

Mysiak, J., Giupponi, C., and Rosato, P.: Towards Development of Decision Support Systems for Environmental Application, Environ. Modell. Softw., 20, 203-214, 2005.

Paul, F., Kääb, A., Maisch, M., Kellenberger, T., and Haeberli, W.: Rapid disintegration of Alpine glaciers observed with satellite data. - Geophys. Res. Lett., 31, L21402, doi:10.1029/2004GL020816, 2004.

Pykh, Y. A., Kennedy, E. T., and Grant, W. E.: An overview of systems analysis methods in delineating environmental quality indices, Ecol. Model., 130(1-3), 25-38, 2000.

Querner, E. P.: Analysis of basin response resulting from climate change and mitigation measures, in: 2002 - regional hydrology: bridging the gap between research and practice, edited by: Van 
Lanen, H. A. J. and Demuth, S., Wallingford, UK, IAHS, IAHS Publ. 274, 77-84, 2002.

Ren, J., Qin, D., Kang, S., Hou, S., Pu, J., and Jing, Z.: Glacier variations and climate warming and drying in the central Himalayas, Chinese Sci. Bull., 49(1), 65-69, 2004.

Schulting, G.: Critical environmental indicators: performance indices and assessment models for sustainable rural development planning, Ecol. Model., 130(1-3), 47-58, 2000.
Subba, B.: Himalayan Waters, The Panos Institute, South Asia, 286 pp., 2001.

Turner, M. G.: Landscape Ecology - the Effect of Pattern on Process, Annu. Rev. Ecol. Syst., 20, 171-197, 1989.

World Bank: The water resources strategy: An Overview Managing and Developing Water Resources to Reduce Poverty, February 2003, World Bank, Washington D.C., USA, 24 pp., 2003. 